\title{
Letter from the Editors-in-Chief
}

This year has generated more growth for our journal. We have moved to a system of continuous publication, allowing papers to be published as they are ready, as opposed to waiting until the end of each term. Authors are able to see the outcome of their work more quickly, and the articles are more immediately accessible to readers. It's been valuable to explore new approaches to publishing to keep pace with the volume and quality of undergraduate research on campus.

The articles in this issue represent a breadth of research across disciplines, methodologies, time periods, and geographies. Each of them brings insightful analysis to original research questions, and offers new perspectives in larger scholarly conversations.

Kendra Schreiner compares the leadership styles and legacies of two influential political figures in southeast Asia, to highlight the significance of not only the leaders' own life histories, but also their subjects' experiences, when explaining how particular personalities come to power. Evaluating current trends in the field of nursing, Kira Marie Olson argues for better testing of nasogastric tube placement methods in order to improve patient care. Arjun Singh Jabbal and Adam Baxter-Jones address a central question for many athletes: which training method is most effective for building endurance. They call for ongoing attention to the issue. Lauren Tarasoff, Leah Ferguson, and Kent Kowalski seek out ways to foster healthy experiences for competitive dancers by examining the kinds of barriers to selfcompassion that dancers themselves may experience. Recognizing pervasive trends in trades professions, Leanne Jaeb, Evan Parker, Courtney Black, and Karissa Cooper examine and measure how sexism can affect workplace safety. Amani Khelifa brings a new analytical lens to accounts about two Indigenous women in the sixteenth and seventeenth centuries, demonstrating the value of reading colonial texts "between the lines" to seek out marginalized voices. Finally, Sarah Wist compares the effectiveness of several types of pesticides for cabbage productivity, with implications not only for home gardeners but also for commercial canola growers and market gardens.

As one of many initiatives at the University of Saskatchewan supporting research at the undergraduate level, USURJ offers the opportunity for students and editors to disseminate undergraduate research and enhance the visibility and accessibility of work that might otherwise go unshared. This endeavour would not be possible without the hard work and dedication of student volunteers, reviewers, authors, and faculty and staff advisors, the Office of the VP Research, and the University Library. We extend our sincere gratitude as we celebrate another successful issue of USURJ.

Katya MacDonald \& Courtney Ballantyne

Graduate and Undergraduate Editors-in-Chief

January 26, 2017 